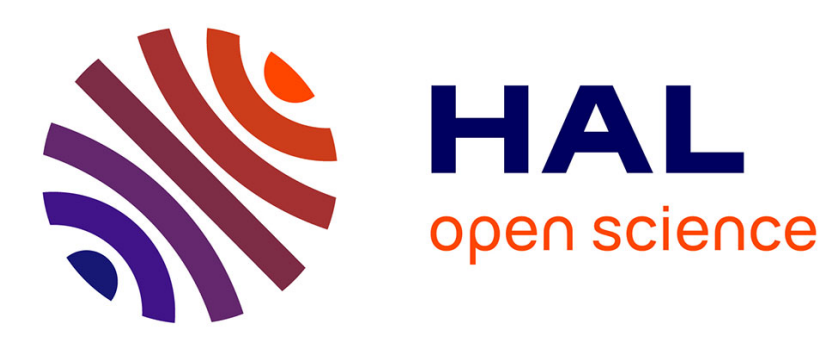

\title{
Acute diffuse interstitial lung disease in adults: Do not overlook lepidic adenocarcinoma of the lung
}

C. Dignoire, G. Beltramo, A. Milière, C. Foignot, A. Zouak, P. Bonniaud, Marjolaine Georges

\section{To cite this version:}

C. Dignoire, G. Beltramo, A. Milière, C. Foignot, A. Zouak, et al.. Acute diffuse interstitial lung disease in adults: Do not overlook lepidic adenocarcinoma of the lung. Respiratory Medicine and Research, 2020, 77, pp.18 - 20. 10.1016/j.resmer.2019.10.002 . hal-03281198

\section{HAL Id: hal-03281198 \\ https://hal.inrae.fr/hal-03281198}

Submitted on 8 Jul 2021

HAL is a multi-disciplinary open access archive for the deposit and dissemination of scientific research documents, whether they are published or not. The documents may come from teaching and research institutions in France or abroad, or from public or private research centers.
L'archive ouverte pluridisciplinaire HAL, est destinée au dépôt et à la diffusion de documents scientifiques de niveau recherche, publiés ou non, émanant des établissements d'enseignement et de recherche français ou étrangers, des laboratoires publics ou privés. 


\section{Acute diffuse interstitial lung disease in adults: Do not overlook lepidic adenocarcinoma of the lung}

\section{A R T I C L E I N F O}

\section{Keywords:}

Non small lung cancer

Lepidic adenocarcinoma

Open lung biopsy

ARDS

Bronchorrhea

Hypoxemia

\section{Introduction}

Primary lung adenocarcinoma is the most common type lung cancer. When it has a predominant lepidic component, it is known as lepidic predominant adenocarcinoma (LPA). We report an atypical case of LPA in patient with acute hypoxemic respiratory distress.

\section{Case report}

A 56-year-old nonsmoking male with no significant past medical history or occupational exposure consulted his general practitioner for cough and breathlessness. The clinical examination found isolated pulmonary crackles in the right lower lobe. The lung CT scan revealed areas of ground glass opacity with consolidation, open bronchus sign, pseudocavitation and poorly defined margins in the posterior segment of the right upper lobe and the right lower lobe (Fig. 1A). He was initially treated with amoxicillin and roxithromycin. One month later (day 0), the patient was referred to our Respiratory Intensive Care Unit (ICU) with rapidly worsening hypoxemia. The clinical examination found only bi-basal crackles. Bronchoalveolar lavage (BAL) cell count demonstrated $40 \%$ neutrophils with atypical cells, culture found $10^{4}$ Pseudomonas aeruginosa and PCR for Pneumocystis jirovecii was slightly positive ( 35 copies $/ \mathrm{ml}$ ). The HIV test was negative as were serologic tests for antibodies. Transthoracic echocardiography was normal. The patient was treated with a combination of ceftazidime, ciprofloxacin and cotrimoxazole, but his condition continued to worsen. On day 7, high-flow humidified nasal oxygenation (HFFNO) was required with $\mathrm{P} / \mathrm{F}$ ratio less than 100 , and $\mathrm{X}$-ray found rapidly extensive opacities. The patient underwent right upper lobe open lung biopsy (OLB) with mini-thoracotomy at day 9. Frozen sections revealed a nonmucinous in situ adenocarcinoma associated with LPA which was later confirmed by histopathology (Fig. 1B). A targeted therapy with erlotinib was started pending EGFR status after multidisciplinary discussion. Significant bronchorrhea ( $200 \mathrm{ml} /$ day) stayed uncontrolled despite corticosteroids then octreotide and required iterative draining of the lungs on a daily basis. The p.G12 V mutation of exon 2 of the KRAS gene was detected. Immunolabeling was negative for PDL1 expression; EGFR and BRAF mutations were not detected; ALK and ROS 1 rearrangements were absent. The patient remained intubated after OLB. Despite the optimization of mechanical ventilation and bronchorrhea, clinical status was getting worse. Gas exchanges and hemodynamics didn't allow cytotoxic chemotherapy in second line treatment. The patient died at day 31 from terminal respiratory failure.

\section{Discussion}

Since 2015, what was formerly called bronchioloalveolar carcinoma was reclassified as in situ carcinoma based on the typical growth pattern of the tumor along the alveolar walls and airways in the outer regions of the lungs. When it becomes invasive, it should be referred to as lepidic predominant adenocarcinoma (LPA) [1]. It is classically a mildly aggressive form of cancer with a slower growth rate and a better prognosis. The most frequent symptoms are progressively worsening cough, sputum, shortness of breath and hemoptysis. Acute respiratory distress is a very rare presentation [2]. Our patient experienced a swift and intense progression to hypoxemic respiratory failure. Our case underlines the fact that invasive adenocarcinoma should be promptly discussed in patients suffering from acute diffuse interstitial lung disease. It is of great importance to characterize the mechanisms of hypoxemic respiratory failure to optimize both the symptomatic treatment and the aetiological treatment. When chest CT or BAL cannot identify any obvious cause, lung biopsy (OLB, transbronchial cryobiopsy, or CT-guided percutaneous lung biopsy) should be discussed in acute respiratory distress. Even if OLB has been linked with high morbi-mortality in this population (ranging from $17 \%$ to $39 \%$ ) [3], decision-making was facilitated by the identification on chest CT of cheerios, a rare radiological sign typically described in LPA [4].

Pemetrexed and platinum combination chemotherapy is the first-line treatment in patients with advanced adenocarcinoma with a performance status score of 0 to 2 . Older studies indicated that LPA might be less sensitive to standard chemotherapy. However, recent work from Lau et al. demonstrated that pemetrexed is effective and well tolerated in LPA [5].

In the last decade, multiple oncogenic driver alterations have been discovered, and each of them represents a potential therapeutic target. Epithelial growth factor receptor (EGFR) is one the most studied oncogenes related to lung adenocarcinoma. LPA is associated with EGFR mutations in up to $45 \%$ of cases [6]. EGFR-tyrosine kinase inhibitors (EGFR-TKIs) used in LPA improve response rates, time to progression and overall survival, and they exhibit low toxicity [7]. Despite higher frequencies of EGFR mutations, the 

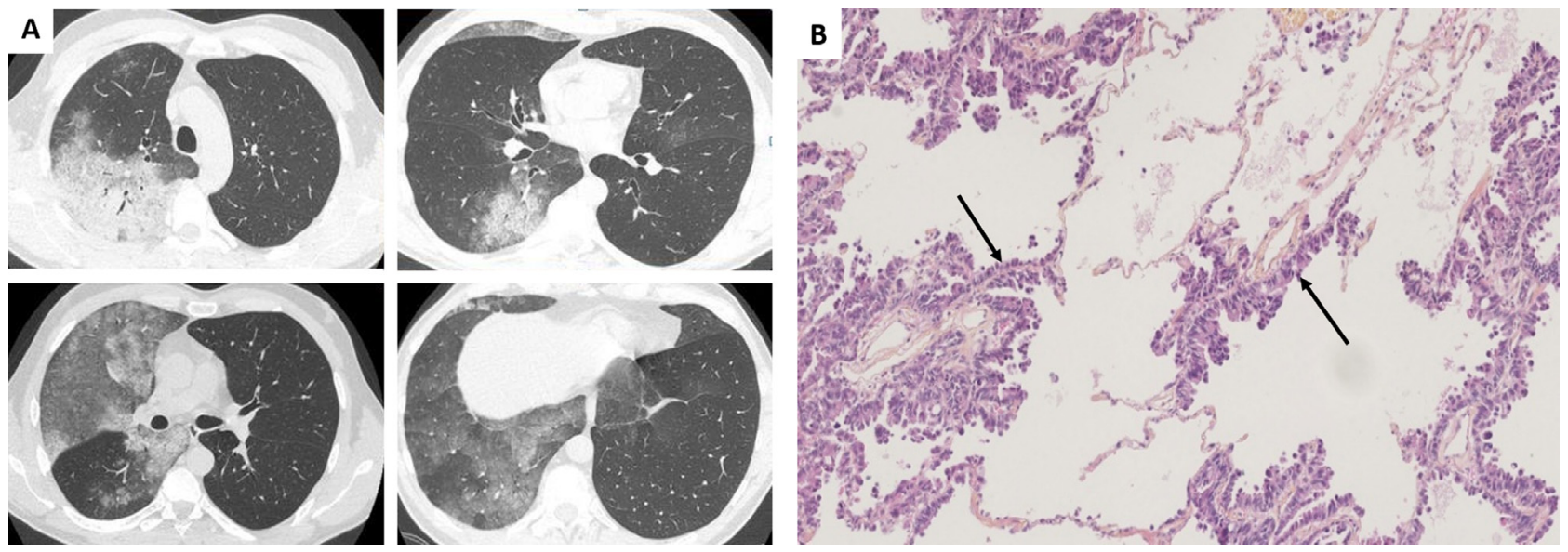

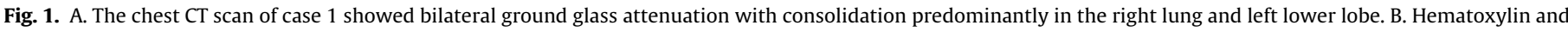

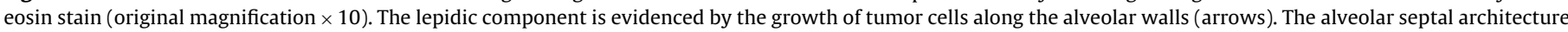
is preserved.

prognosis of advanced LPA with diffuse infiltrate was not dramatically improved with the use of EGFR-TKIs, and median survival remains approximately 1 year. The efficacy of EGFR-TKIs seems to differ between the histologic subtype. In mucinous subtypes, the incidence of EGFR mutation is rare and KRAS mutation is frequent ranging from 67 to $86 \%[8,9]$. The most frequent KRAS mutation is G12D (67\%) followed by G12 V (24\%), G12 C (5\%) and G12A (5\%) [10]. G12V KRAS mutation is especially observed in non-smokers [11]. Genetic alterations of EGFR and KRAS typically are mutually exclusive but a few cases have been reported with concomitant EGFR and KRAS mutations [10]. Currently, G12 V KRAS mutant patients treated with platinum-based chemotherapy tend to have a higher response rate and longer progression-free survival [11]. The use of lung transplant for the diffuse form of the disease has been justified in certain cases because LPA is a potentially lung-limited malignancy with a low rate of extrathoracic metastases. Thus far, fewer than 100 lung transplants have been reported for advanced LPA. Overall survival was similar to that of the general transplant population with approximately half the patients surviving to 5 years. However, the reported rate of recurrence is high, up to $59 \%$ of patients [12].

\section{Conclusion}

Clinicians should carefully search for evidence of lung malignancies in patients hospitalized for acute hypoxemic diffuse interstitial lung disease without obvious infectious aetiology. The presence of cheerios should justify lung biopsy despite the known risks. Early identification of LPA allows the early implementation of specific innovative treatments including pemetrexed or EGFR-TKIs, increasing the chances of a favorable outcome. Prompt diagnosis may also be beneficial for end-of-life therapeutic discussions.

\section{Disclosure of interest}

The authors declare that they have no competing interest.

\section{Acknowledgments}

The authors thank Suzanne Rankin for reviewing the manuscript.

\section{References}

[1] Travis WD, Brambilla E, Noguchi M, et al. International association for the study of lung cancer/american thoracic society/european respiratory society international multidisciplinary classification of lung adenocarcinoma. J Thorac Oncol 2011;6:244-85.

[2] Venkata C, Mireles JA, Venkateshiah SB. Refractory hypoxemic respiratory failure due to adenocarcinoma of the lung with predominant bronchioloalveolar carcinoma component. Respiratory Care 2009;54:1496-9.

[3] Papazian L, Thomas P, Bregeon F, et al. Open-lung biopsy in patients with acute respiratory distress syndrome. Anesthes 1998;88:935-44.

[4] Tailor TD, Schmidt RA, Eaton KD, Wood DE, Pipavath SNJ. The pseudocavitation sign of lung adenocarcinoma: a distinguishing feature and imaging biomarker of lepidic growth. J Thorac Imaging 2015;30:308-13.

[5] Lau DHM, Moon J, Davies AM, et al. Southwestern oncology group phase II trial (S0526) of pemetrexed in bronchioloalveolar carcinoma subtypes of advanced adenocarcinoma. Clin Lung Cancer 2013;14:351-5.

[6] Sun PL, Seol H, Lee HJ, Yoo SB, Kim H, Xu X, et al. High incidence of EGFR mutations in Korean men smokers with no intratumoral heterogeneity of lung adenocarcinomas: correlation with histologic subtypes EGFR/TTF-1 expressions, and clinical features. J Thorac Oncol 2012;7:323-30.

[7] Cadranel J, Quoix E, Baudrin L, Mourlanette P, Moro-Sibilot D, Morere JF, et al. IFCT-0401 Trial: a phase II study of gefitinib administered as first-line treatment in advanced adenocarcinoma with bronchioloalveolar carcinoma subtype. J Thorac Oncol 2009;4:1126-35.

[8] Finberg KE, Sequist LV, Joshi VA, et al. Mucinous differentiation correlates with absence of EGFR mutation and presence of KRAS mutation in lung adenocarcinoma with bronchioloalveolar features. J Mol Diagn 2007;9: 320-6.

[9] Sakuma Y, Matsuoka S, Yoshihara M, et al. Distinctive evaluation of nonmucinous and mucinous subtypes of bronchioloalveolar carcinomas in EGFR and K-ras gene-mutation analyses for japanese lung adenocarcinoma. Am J Clin Pathol 2007:128:100-8.

[10] Hata A, Katakami N, Fujita S, et al. Frequency of EGFR and KRAS mutations in Japanese patients with lung adenocarcinoma with features of the mucinous subtype of bronchioloalveolar carcinoma. J Thorac Oncol 2010;5: 1197-200.

[11] Cserepes M, Ostoros G, Lohinai Z, et al. Subtype-specific K.R.A.S. mutations in advanced lung adenocarcinoma: a retrospective study of patients treated with platinum-based chemotherapy. Eur J Cancer 2014:50:1819-28.

[12] de Perrot M, Chernenko S, Waddell TK, et al. Role of lung transplantation in the treatment of bronchogenic carcinomas for patients with end-stage pulmonary disease. J Clin Oncol 2004;22:4351-6.
C. Dignoire ${ }^{a, b}$ G. Beltramo ${ }^{\mathrm{a}, \mathrm{b}, \mathrm{c}}$

A. Milière ${ }^{b, d}$ C. Foignot ${ }^{\mathrm{a}, \mathrm{b}, \mathrm{c}}$

A. Zouak ${ }^{a}$

P. Bonniaud a,b,c M. Georges ${ }^{\mathrm{a}, \mathrm{b}, \mathrm{e}, *}$ 
a Department of Respiratory Diseases and Intensive Care, Reference Center for Adult Rare Pulmonary Diseases, University Hospital of Dijon, 21000 Dijon, France

b University Burgundy Franche-Comté, 21000 Dijon, France

c Inserm U1231, University Burgundy Franche-Comté, 21000 Dijon, France

d Department of Histopathology, University Hospital Dijon, 21000 Dijon, France e Centre des Sciences du Goût et de l'Alimentation, UMR 6265 CNRS 1234 INRA, University Burgundy Franche-Comté, 21000 Dijon, France
* Corresponding author at: Service de Pneumologie et Soins Intensifs Respiratoires, Hôpital François Mitterrand, CHU Dijon-Bourgogne, 14, rue Paul-Gaffarel, Dijon cedex, 21079, France. E-mail address: marjolaine.georges@chu-dijon.fr

(M. Georges)

Received 10 September 2019

Received in revised form 3 October 2019

Accepted 14 October 2019 Available online 31 October 2019 